\title{
Concise Syntheses of Trifluoromethylated Cyclic and Acyclic Analogues of cADPR
}

\author{
Xiangchen Huang, Min Dong, Jian Liu, Kehui Zhang, Zhenjun Yang, Liangren Zhang * \\ and Lihe Zhang
}

State Key Laboratory of Natural and Biomimetic Drugs, School of Pharmaceutical Sciences, Peking University, Beijing 100191, China

* Author to whom correspondence should be addressed; E-Mail: liangren@bjmu.edu.cn; Tel.: +86 10-82802567; Fax: +86 10-82805063.

Received: 6 November 2010; in revised form: 17 November 2010/Accepted: 22 November 2010 / Published: 30 November 2010

\begin{abstract}
A novel trifluoromethylated analogue of cADPR, 8- $\mathrm{CF}_{3}-\mathrm{cIDPDE}$ (5) was designed and synthesized via construction of $N^{1}, N^{9}$-disubstituted hypoxanthine, trifluoromethylation and intramolecular condensation. A series of acyclic analogues of cADPR were also designed and synthesized. These compounds could be useful molecules for studying the structure-activity relationship of cADPR analogues and exploring the cADPR/RyR $\mathrm{Ca}^{2+}$ signalling system.
\end{abstract}

Keywords: cADPR analogue; acyclic cADPR analogue; trifluoromethylation; synthesis

\section{Introduction}

Cyclic adenosine diphosphate ribose (cADPR, 1, Figure 1), isolated from sea urchin eggs [1], is a metabolite of $\beta$-nicotinamide adenine dinucleotide $\left(\mathrm{NAD}^{+}\right)$. It has been proved that cADPR is a signalling molecule, which regulates calcium mobilization via ryanodine receptor ( $\mathrm{RyR}$ ) in a wide variety of $\mathrm{Ca}^{2+}$-dependent cellular responses such as fertilization, secretion, contraction, proliferation and so on [2]. Since the discovery of cADPR, numerous works have been done on the synthesis of cADPR analogues to search for agonists or antagonists of cADPR/RyR $\mathrm{Ca}^{2+}$ signalling system [3-5].

In our previous work, a series of cADPR analogues in which the southern and/or northern ribose was replaced by an ether chain were synthesized [6,7]. Most of those compounds, such as cIDPRE (2) and cIDPDE (3), are membrane permeate agonists in Jurkat T cells. 
Figure 1. Structures of cADPR and its analogues.
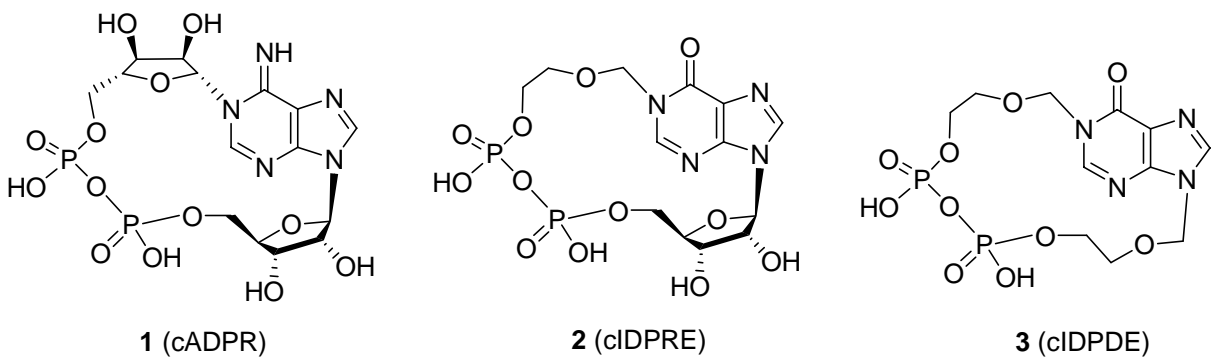

Moreover, it was found that those agonists antagonize the hydrolysis of CD38. Substitution at C-8 of purine affects the agonistic activity of cADPR analogues. For example, 8- $\mathrm{Br}$ or 8-Cl substituted cIDPRE loses activity; however, the activity is retained for $8-\mathrm{N}_{3}$ or $8-\mathrm{NH}_{2}$ substituted cIDPRE. These results indicate that the effect of substitution at 8-position depends on the property of the substituent group. The trifluoromethyl group, possessing high electronegativity and lipophilicity, usually alters considerably the overall charge distribution and enhances the membrane permeability of molecules. Since the trifluoromethyl group imparts a variety of special physical and chemical properties to molecules, a number of trifluoromethylated compounds exhibit enhanced biological activity [8]. Taking these points into account, we synthesized $8-\mathrm{CF}_{3}-\mathrm{CIDPRE}$ (4, Figure 2). We found that this compound was also a membrane permeate calcium agonist in Jurkat $T$ cells [9]. In this study, the trifluoromethyl group is introduced to cIDPDE (8- $\mathrm{CF}_{3}$-cIDPDE, 5, Figure 2). This compound provides a complementary agent for understanding the effect of 8 -substitution on calcium signalling property.

Figure 2. Structures of compounds 4-8.

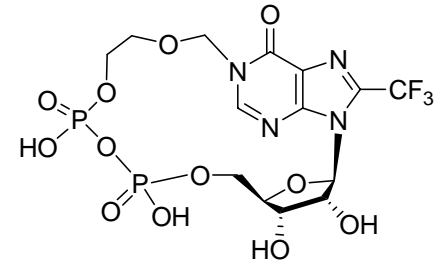

$4\left(8-\mathrm{CF}_{3}\right.$-CIDPRE)

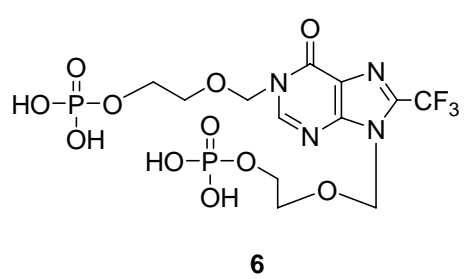

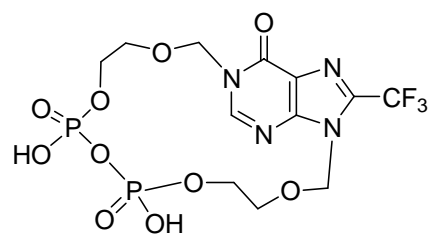

$5\left(8-\mathrm{CF}_{3}-\mathrm{CIDPDE}\right)$

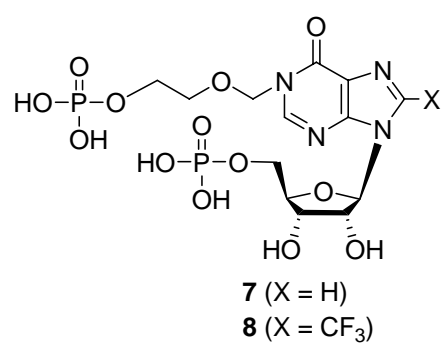

cADPR can be hydrolyzed either in vivo or in vitro [10,11]. The cyclic pyrophosphate moiety, as one of the most vulnerable linkages in cADPR, can be hydrolyzed by $\mathrm{Mn}^{2+}$-dependent ADP-ribose/CDP-alcohol pyrophospatase to afford the bisphosphate metabolite [12]. Recently, a series of acyclic analogues of cADPR, in which the pyrophosphate moiety is cleaved to give a bisphosphate, have been synthesized [13]. The primary pharmacological research revealed that some of them could inhibit cIDPRE-induced $\mathrm{Ca}^{2+}$ release. To further explore the $\mathrm{Ca}^{2+}$-modulating activities of this novel 
class of cADPR mimics and their mechanism further, we have designed and synthesized acyclic analogues of cIDPRE and the trifluoromethylated analogues 6-8 (Figure 2).

\section{Results and Discussion}

\subsection{Synthesis of $8-C F_{3}-c I D P D E(5)$}

The synthesis of 8-CF $\mathrm{CF}_{3}$-cIDPDE is summarized in Scheme 1. Starting from 8-bromoadenine [14], $N^{9}$-substitution was carried out with (2-acetoxyethoxy)methyl bromide [15] in the presence of potassium tert-butoxide ( $t$-BuOK) and 18-crown-6 [16] to afford 10 in 44\% yield. It is noteworthy that when (2-acetoxyethoxy)methyl chloride was employed instead, replacement of the 8-bromo group with a chlorine atom was observed. The structure of compound $\mathbf{1 0}$ was confirmed by ${ }^{1} \mathrm{H}-\mathrm{NMR}$, ${ }^{13} \mathrm{C}-\mathrm{NMR}, \mathrm{HMBC}$ and HR-ESI-MS spectra. In the HMBC spectrum of 10, the correlation between $\mathrm{H}-1^{\prime}$ of the ether chain and $\mathrm{C}-4$ and $\mathrm{C}-8$ of adenine base were observed, which verified that the substitution was on N-9.

Scheme 1. Synthesis of 8-CF - -cIDPDE (5).<smiles>CC(C)(C)OCCOCn1c(Br)nc2c(N)ncnc21</smiles>

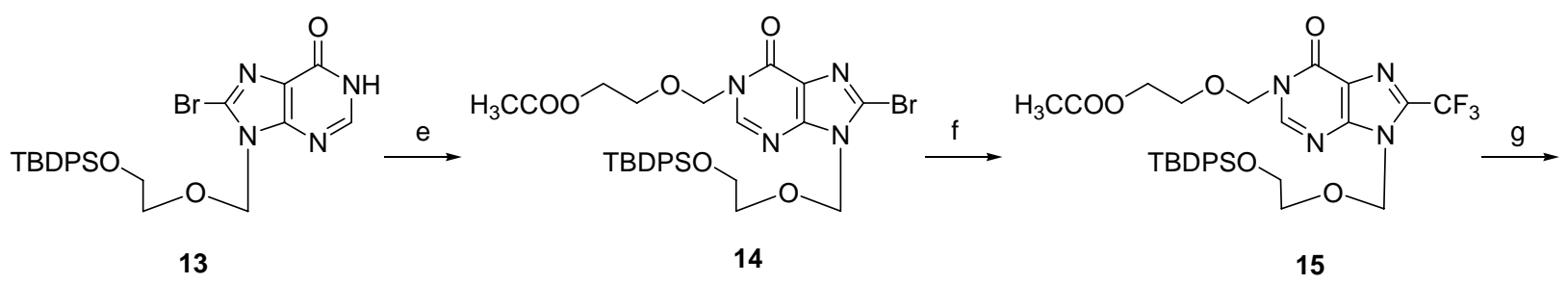<smiles>CC(=O)OCCOCn1cnc2c(nc(C(F)(F)F)n2COCCO)c1=O</smiles>

16

17

18<smiles>O=c1c2nc(C(F)(F)F)n(COCCOP(=O)(O)O)c2ncn1COCCOP(=O)(O)OP(=O)(O)OCCOCn1cnc2c(nc(C(F)(F)F)n2COCCOP(=O)(O)O)c1=O</smiles>

Reagents and conditions: (a) $t$ - $\mathrm{BuOK}, 18$-crown-6, $\mathrm{BrCH}_{2} \mathrm{OCH}_{2} \mathrm{CH}_{2} \mathrm{OAc}$, THF, $0{ }^{\circ} \mathrm{C}$; (b) $\mathrm{K}_{2} \mathrm{CO}_{3}$, $\mathrm{MeOH}$, rt; (c) $\mathrm{NaNO}_{2}, \mathrm{AcOH}, \mathrm{rt}$; (d) TBDPSCl, imidazole, DMF, rt; (e) DBU, $\mathrm{ClCH}_{2} \mathrm{OCH}_{2} \mathrm{CH}_{2} \mathrm{OAc}, \mathrm{CH}_{2} \mathrm{Cl}_{2}$, rt; (f) $\mathrm{FSO}_{2} \mathrm{CF}_{2} \mathrm{CO}_{2} \mathrm{Me}$, CuI, HMPA, DMF, $70{ }^{\circ} \mathrm{C}$; (g) $70 \% \mathrm{HF} \cdot \mathrm{Py}$, THF; (h) PSS, TPSCl, tetrazole, Py, rt; (i) $\mathrm{AcCl}, \mathrm{MeOH}$; (j) i. $\mathrm{POCl}_{3} / \mathrm{DIPEA}, \mathrm{CH}_{3} \mathrm{CN}, 0{ }^{\circ} \mathrm{C}$; ii. $1 \mathrm{M}$ TEAB, pH 7.5, rt; (k) I $2,3 \AA$ MS, Py, rt. 
Deacetylation of 10 with $\mathrm{K}_{2} \mathrm{CO}_{3} / \mathrm{MeOH}$ gave compound 11, and after diazotization, and protection of the 5'-hydroxyl group with a tert-butyldiphenylsilyl (TBDPS) group, 13 was obtained. An $N^{1}$-substitution was carried out on compound 13 with (2-acetoxyethoxy)methyl chloride in the presence of excess 1,8-diazabicyclo[5.4.0] undec-7-ene (DBU) to afford 14 in 61\% yield. Since both of the $N^{1}$ and the $O^{6}$ have nucleophilicity, the $N^{1}$-isomer and $O^{6}$-isomer were obtained (Figure 3). The structure of 14 was confirmed by ${ }^{1} \mathrm{H}-\mathrm{NMR},{ }^{13} \mathrm{C}-\mathrm{NMR}, \mathrm{HMBC}$ and HR-ESI-MS spectra. In the HMBC spectrum of 14, the correlation between $\mathrm{H}-1$ "of the northern ether chain and C-2 of hypoxanthine base, and that between $\mathrm{C}-1^{\prime \prime}$ of the northern ether chain and $\mathrm{H}-2$ of hypoxanthine base were both observed, which were similar to that of $N^{l}$-isomer. Corresponding correlations were not found in the HMBC spectrum of the $O^{6}$-substituted side product.

Figure 3. Structures of 14 and its $O^{6}$-isomer.

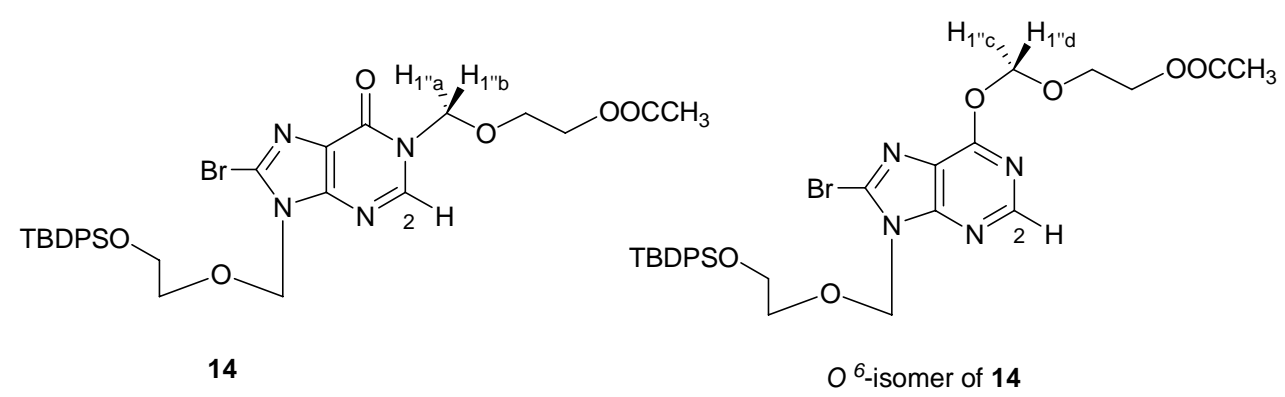

The unstable glycosylic bond in nucleosides is sensitive to certain conditions, which causes great difficulties in the trifluoromethylation of nucleosides. In our previous work, methyl fluorosulphonyldifluoroacetate/copper iodide $\left(\mathrm{FSO}_{2} \mathrm{CF}_{2} \mathrm{CO}_{2} \mathrm{Me} / \mathrm{CuI}\right)$ [17] was initially applied to the synthesis of 8- $\mathrm{CF}_{3}$-purine nucleosides [9]. Adopting this strategy, trifluoromethylation of $\mathbf{1 4}$ was achieved successfully, and optimization of this reaction was carried out (Table 1). Under the optimal reaction conditions, 15 was obtained in $42 \%$ yield, and 14 was recovered in 17\% yield. Interestingly, compound 16 was also obtained in a yield of 14\%. It is known that the tert-butyldimethylsilyl (TBDMS) group and TBDPS group could be removed by tetrabutylammonium fluoride/tetrahydrofuran (TBAF/THF), potassium fluoride and other agents containing fluoride [18]. Accordingly, we deduced it was the fluoride ion generated in the process of trifluoromethylation [17] that facilitated the removal of the $5^{\prime}-O$-TBDPS group. The trifluoromethylated product 15 was characterized by ${ }^{1} \mathrm{H}-\mathrm{NMR},{ }^{13} \mathrm{C}-\mathrm{NMR}$, ${ }^{19} \mathrm{~F}-\mathrm{NMR}$ and HR-ESI-MS spectra. In the ${ }^{13} \mathrm{C}$-NMR spectrum of compound 15 , signals of the $\mathrm{CF}_{3}$ group and C-8 were spilt into two quartets, with ${ }^{1} J_{\mathrm{CF}}=270 \mathrm{~Hz}$ and ${ }^{2} J_{\mathrm{CF}}=41 \mathrm{~Hz}$, respectively, and the singlet at -63.358 ppm was observed in the ${ }^{19}$ F-NMR spectrum. These data strongly support the incorporation of the trifluoromethyl group.

Table 1. Optimization of the reaction conditions of trifluoromethylation.

\begin{tabular}{ccc}
\hline Entry & $\mathbf{F S O}_{2} \mathbf{C} \mathbf{F}_{2} \mathbf{C O} \mathbf{M e} / \mathbf{H M P A}$ & Yield \\
\hline 1 & 5 equiv & trace \\
2 & 10 equiv & $12 \%$ \\
3 & 15 equiv & $42 \%$ \\
4 & 20 equiv & $31 \%$ \\
5 & 30 equiv & $18 \%$ \\
\hline
\end{tabular}


The 5'-O-TBDPS group in compound 15 was removed by employing 70\% HF-pyridine [19]. The strong electronegativity of trifluoromethyl group at C-8 of hypoxanthine makes the glycosylic bond rather sensitive to acid conditions. Hence, 70\% HF-pyridine was added dropwise to the reaction mixture at $-20{ }^{\circ} \mathrm{C}$. Compound 16 was successfully converted to $\mathbf{1 7}$ by the reaction with $S, S$-diphenylphosphorodithioate (PSS) [20] in the presence of triisopropylbenzenesulfonyl chloride (TPSCl) and tetrazole in pyridine, in a yield of $79 \%$. Considering the instability of phenylthio group under basic conditions [21], acetyl chloride in methanol $(\mathrm{AcCl} / \mathrm{MeOH})$ [22] was applied to the deacetylation of 17. When 1.2 equivalent of $\mathrm{AcCl}$ was utilized, compound $\mathbf{1 7}$ was successfully converted to 18. Phosphorylation of the 5"-hydroxyl in $\mathbf{1 8}$ was carried out in the presence of excess $\mathrm{POCl}_{3}$ and $\mathrm{N}, \mathrm{N}$-diisopropylethylamine (DIPEA) at $0{ }^{\circ} \mathrm{C}$. After being stirred for $14 \mathrm{~h}$, the mixture was treated with $1 \mathrm{M}$ triethylammonium bicarbonate (TEAB) for $6 \mathrm{~h}$ at room temperature [23], which facilitated the semi-deprotection of the $S, S$-diphenylphosphate. Purified by high performance liquid chromatography (HPLC), compound 19 was obtained as its triethylammonium salt.

Following the Matsuda strategy [24], with excess $\mathrm{I}_{2}$ and $3 \AA$ molecular sieves as promoters, the intramolecular cyclization was performed in pyridine by adding a solution of compound $\mathbf{1 9}$ slowly over $20 \mathrm{~h}$ utilizing a syringe pump. Purification by HPLC afforded cyclic product 5 as its triethylammonium salt in $71 \%$ yield, which was characterized by ${ }^{1} \mathrm{H}-\mathrm{NMR},{ }^{19} \mathrm{~F}-\mathrm{NMR},{ }^{31} \mathrm{P}-\mathrm{NMR}$ and HR-ESI-MS spectra.

\subsection{Syntheses of Compounds 6-8}

Deacetylation of 16 with $\mathrm{K}_{2} \mathrm{CO}_{3} / \mathrm{MeOH}$ afforded compound 20 (Scheme 2), then both of the free hydroxyl groups in 20 were phosphorylated by employing $\mathrm{POCl}_{3} / \mathrm{DIPEA}$ in $\mathrm{CH}_{3} \mathrm{CN}$ at $0{ }^{\circ} \mathrm{C}$ for $16 \mathrm{~h}$, followed by the treatment with $1 \mathrm{M}$ TEAB for $6 \mathrm{~h}$. Purified by HPLC, the target molecule 6 was obtained as its triethylammonium salt in $62 \%$ yield for two steps.

Scheme 2. Syntheses of compounds 6-8.

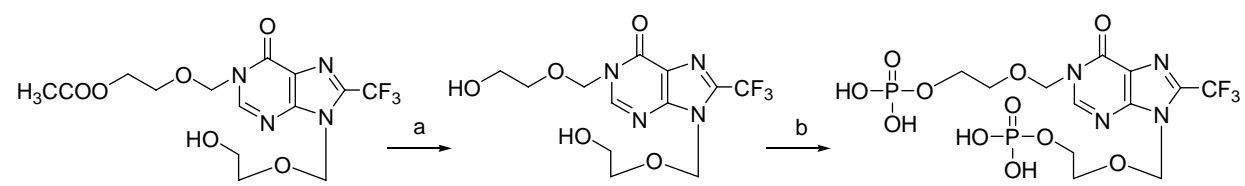

16

20

6
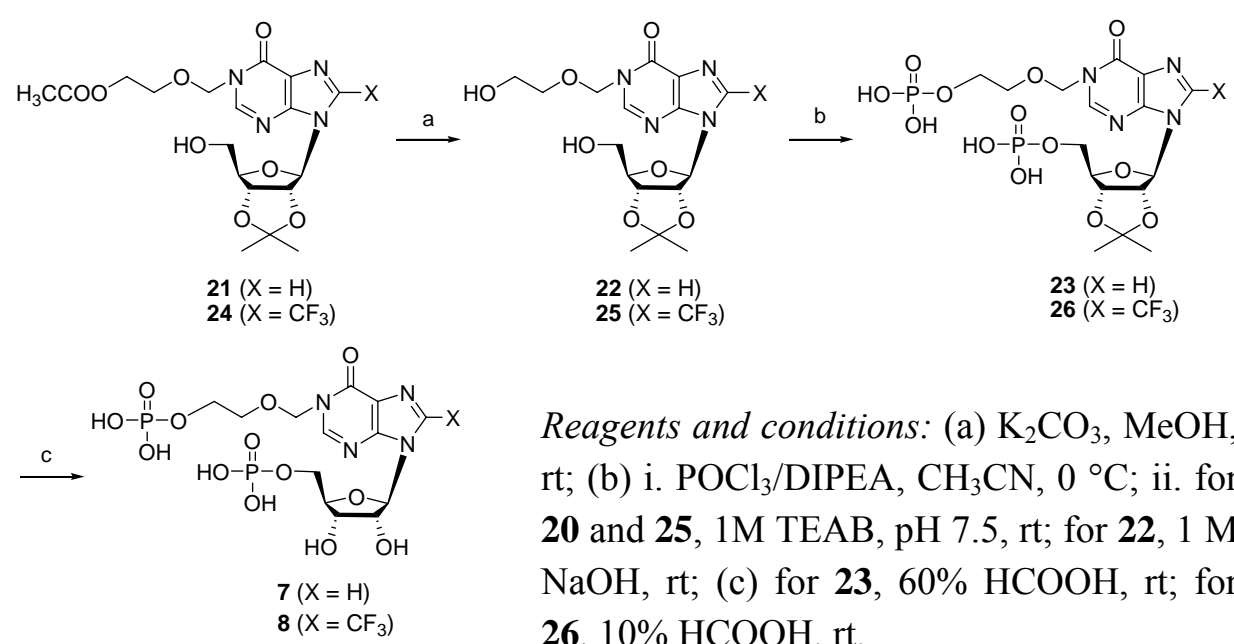

Reagents and conditions: (a) $\mathrm{K}_{2} \mathrm{CO}_{3}, \mathrm{MeOH}$, rt; (b) i. $\mathrm{POCl}_{3} / \mathrm{DIPEA}, \mathrm{CH}_{3} \mathrm{CN}, 0{ }^{\circ} \mathrm{C}$; ii. for 20 and 25, 1M TEAB, pH 7.5, rt; for 22, $1 \mathrm{M}$ $\mathrm{NaOH}, \mathrm{rt}$; (c) for $23,60 \% \mathrm{HCOOH}$, rt; for 26, $10 \% \mathrm{HCOOH}$, rt. 
Compound 23 was synthesized from 21 [6] in a yield of 71\% for two steps by a similar method as used for the preparation of 6 . After removing the $2^{\prime}, 3^{\prime}-O$-isopropylidene group using $60 \% \mathrm{HCOOH}$ solution, compound 7 was obtained as its triethylammonium salt in $85 \%$ yield. Starting from compound 24 [9], 26 was synthesized by a similar procedure. Considering the sensitivity of 8- $\mathrm{CF}_{3}$-purine nucleosides to acid conditions, we performed the deprotection of $\mathbf{2 6}$ by employing $10 \%$ rather than $60 \% \mathrm{HCOOH}$ solution, which afforded compound $\mathbf{8}$, with little de-glycosylated side product being generated. After purification by HPLC, the target molecule $\mathbf{8}$ was obtained as its triethylammonium salt in $68 \%$ yield, with 26 recovered in a yield of $15 \%$. The biological activity assay of all the compounds synthesized is underway.

\section{Experimental}

\subsection{General}

HR-ESI-MS and ESI-MS were performed with a Bruker BIFLEX III instrument. ${ }^{1} \mathrm{H}-\mathrm{NMR}$ and ${ }^{13} \mathrm{C}-\mathrm{NMR}$ were recorded with a Bruker AVANCE III 400; $\mathrm{CDCl}_{3}$, DMSO- $d 6$ or $\mathrm{D}_{2} \mathrm{O}$ were used as a solvent. Chemical shifts are reported in parts per million downfield from TMS $\left({ }^{1} \mathrm{H}\right.$ and $\left.{ }^{13} \mathrm{C}\right) .{ }^{31} \mathrm{P}-\mathrm{NMR}$ spectra were recorded at room temperature by use of a JEOL AL300 spectrometer $(121.5 \mathrm{MHz})$ or JEOL ECA600 spectrometer (243 MHz). Orthophosphoric acid (85\%) was used as external standard. ${ }^{19}$ F- NMR spectra were recorded on a Varian VXR-500 spectrometer (470 MHz). Chemical shifts of ${ }^{19} \mathrm{~F}$ - NMR are reported in ppm with reference to $\mathrm{CF}_{3} \mathrm{COOH}$ as external standard. Compounds 19, 23, 26, and 5-8 were purified on an Alltech preparative $\mathrm{C}_{18}$ reversed-phase column $(2.2 \times 25 \mathrm{~cm})$ with a Gilson HPLC using MeCN/TEAB (pH 7.5) buffer system as eluent.

\subsection{Synthesis}

$N^{9}$-[(5'-Acetoxyethoxy)methyl]-8-bromoadenine (10). To a stirred suspension of 8-bromoadenine (4.5 g, $21.03 \mathrm{mmol})$ [14] in anhydrous THF $(400 \mathrm{~mL})$ was added potassium tert-butoxide $(2.59 \mathrm{~g}, 23.13 \mathrm{mmol})$ and 18-crown-6 $(1.11 \mathrm{~g}, 4.20 \mathrm{mmol})$. The reaction mixture was stirred at room temperature for $15 \mathrm{~min}$, and then $\mathrm{BrCH}_{2} \mathrm{OCH}_{2} \mathrm{CH}_{2} \mathrm{OAc}(3.1 \mathrm{~mL}, 23.13 \mathrm{mmol})$ [15] was added dropwise at $0{ }^{\circ} \mathrm{C}$. After being stirred for $30 \mathrm{~min}$ at $0{ }^{\circ} \mathrm{C}$, the mixture was filtered and the filtrate is evaporated under reduced pressure. The residue was purified by silica gel column chromatography $(\mathrm{PE}-\mathrm{EA}=1: 2)$ to afford compound 10 (3.02 g, 44\%). ${ }^{1} \mathrm{H}-\mathrm{NMR}$ (400 MHz, DMSO-d6) $\delta 1.92$ (s, 3H, OAc), 3.69-3.72 (m, $2 \mathrm{H}, \mathrm{H}_{4}{ }^{\prime}$ ), 4.04-4.17 $\left(\mathrm{m}, 2 \mathrm{H}, \mathrm{H}_{5}\right)^{\prime}, 5.51\left(\mathrm{~s}, 2 \mathrm{H}, \mathrm{H}_{1}\right), 7.48\left(\mathrm{~s}, 2 \mathrm{H}, \mathrm{NH}_{2}\right), 8.16\left(\mathrm{~s}, 1 \mathrm{H}, \mathrm{H}_{2}\right) \cdot{ }^{13} \mathrm{C}-\mathrm{NMR}(100 \mathrm{MHz}, \mathrm{DMSO}-d \sigma) \delta$ $170.1,154.8,153.2,151.2,126.5,118.7,72.3,67.0,62.7,20.5 . \mathrm{MS}\left(\mathrm{ESI}_{-} \mathrm{TOF}^{+}\right): m / z=330.0\left[(\mathrm{M}+\mathrm{H})^{+}\right]$.

$N^{9}$-[(5'-Hydroxylethoxy)methyl]-8-bromohypoxanthine (12). Compound 10 (1.43 g, $\left.4.34 \mathrm{mmol}\right)$ was dissolved in methanol $(120 \mathrm{~mL})$. To the solution was added $\mathrm{K}_{2} \mathrm{CO}_{3}(73 \mathrm{mg}, 0.53 \mathrm{mmol})$ and stirred for $6 \mathrm{~h}$ at room temperature. The mixture was neutralized by addition of $0.1 \mathrm{M} \mathrm{HCl}$ solution, and evaporated under reduced pressure. The residue was dissolved in $\mathrm{AcOH}(70 \mathrm{~mL})$, and a solution of $\mathrm{NaNO}_{2}(2.52 \mathrm{~g}, 36.4 \mathrm{mmol})$ in $\mathrm{H}_{2} \mathrm{O}(17 \mathrm{~mL})$ was added. The resulting mixture was stirred at room temperature for $24 \mathrm{~h}$. After the mixture was evaporated in vacuo, the residue was partitioned between $\mathrm{CHCl}_{3}$ and $\mathrm{H}_{2} \mathrm{O}$. The aqueous phase was extracted again with $\mathrm{CHCl}_{3}$, the organic layer was combined 
and washed with brine, dried $\left(\mathrm{Na}_{2} \mathrm{SO}_{4}\right)$, filtered and concentrated in vacuo. Flash chromatography $\left(\mathrm{CH}_{2} \mathrm{Cl}_{2}-\mathrm{MeOH}=40: 1\right)$ afforded $12(792 \mathrm{mg}, 63 \%$ for two steps $) .{ }^{1} \mathrm{H}-\mathrm{NMR}$ (400 MHz, DMSO-d6) $\delta$ 3.46-4.51 (m, 4H, $\left.\mathrm{H}_{4}{ }^{\prime}, \mathrm{H}_{5}{ }^{\prime}\right), 4.63(\mathrm{~s}, 1 \mathrm{H}, \mathrm{OH}), 5.32\left(\mathrm{~s}, 2 \mathrm{H}, \mathrm{H}_{1}{ }^{\prime}\right), 8.14\left(\mathrm{~s}, 1 \mathrm{H}, \mathrm{H}_{2}\right), 12.56(\mathrm{~s}, 1 \mathrm{H}, \mathrm{NH}) . \mathrm{MS}$ $\left(\mathrm{ESI}_{-} \mathrm{TOF}^{+}\right): m / z=289.2\left[(\mathrm{M}+\mathrm{H})^{+}\right]$.

$N^{9}$-[(5'-tert-Butyldiphenylsilyloxyethoxy)methyl]-8-bromohypoxanthine (13). To a solution of 12 (700 mg, $2.42 \mathrm{mmol})$ in anhydrous DMF (10 mL) was added imidazole (1.86 g, $24.2 \mathrm{mmol})$ and tert-butyldiphenylsilyl chloride $(3.4 \mathrm{~mL}, 12.1 \mathrm{mmol})$ under argon, and the mixture was stirred at room temperature for $12 \mathrm{~h}$. And the mixture was evaporated in vacuo, the residue was partitioned between $\mathrm{CH}_{2} \mathrm{Cl}_{2}$ and $\mathrm{H}_{2} \mathrm{O}$. The aqueous phase was extracted again with $\mathrm{CH}_{2} \mathrm{Cl}_{2}$, the organic layer was combined and washed with brine, dried $\left(\mathrm{Na}_{2} \mathrm{SO}_{4}\right)$, filtered and concentrated in vacuo. Flash chromatography $(\mathrm{PE}-$ acetone $=5: 1)$ afforded compound $13(1.21 \mathrm{~g}, 95 \%) .{ }^{1} \mathrm{H}-\mathrm{NMR}\left(400 \mathrm{MHz}, \mathrm{CDCl}_{3}\right) \delta 1.06(\mathrm{~s}, 9 \mathrm{H}$, $\left.\left(\mathrm{CH}_{3}\right)_{3} \mathrm{C}-\right)$, 3.71-3.73 (m, 2H, H4 $\left.{ }^{\prime}\right), 3.82-3.84\left(\mathrm{~m}, 2 \mathrm{H}, \mathrm{H}_{5}{ }^{\prime}\right), 5.66\left(\mathrm{~s}, 2 \mathrm{H}, \mathrm{H}_{1}{ }^{\prime}\right), 7.37-7.69(\mathrm{~m}, 10 \mathrm{H}, \mathrm{ArH})$, $8.44\left(\mathrm{~s}, 1 \mathrm{H}, \mathrm{H}_{2}\right), 13.19(\mathrm{~s}, 1 \mathrm{H}, \mathrm{NH}) .{ }^{13} \mathrm{C}-\mathrm{NMR}\left(100 \mathrm{MHz}, \mathrm{CDCl}_{3}\right) \delta 157.8,150.8,146.3,135.5,133.3$, 129.6, 127.6, 126.4, 124.6, 77.3, 77.0, 76.7, 73.5, 71.1, 62.9, 26.7, 19.0. HRMS (ESI-TOF ${ }^{+}$): calcd for $\mathrm{C}_{24} \mathrm{H}_{27} \mathrm{BrN}_{4} \mathrm{O}_{3} \mathrm{Si}\left[(\mathrm{M}+\mathrm{H})^{+}\right]$527.1109, $\left[(\mathrm{M}+\mathrm{Na})^{+}\right]$549.0928, $\left[(\mathrm{M}+\mathrm{K})^{+}\right]$565.0662; found, 527.1109, 549.0931, 565.0667.

$N^{1}$-[(5"-Acetoxyethoxy)methyl]-N" $N^{9}$-[(5'-tert-butyldiphenylsilyloxyethoxy)methyl]-8-bromohypoxanthine (14). To the solution of $13(1.23 \mathrm{~g}, 2.33 \mathrm{mmol})$ and DBU $(3.5 \mathrm{~mL}, 23.3 \mathrm{mmol})$ in anhydrous $\mathrm{CH}_{2} \mathrm{Cl}_{2}$ (25 mL) was added $\mathrm{ClCH}_{2} \mathrm{OCH}_{2} \mathrm{CH}_{2} \mathrm{OAc}(1.8 \mathrm{~mL}, 11.65 \mathrm{mmol})$ [15] dropwise at $0{ }^{\circ} \mathrm{C}$. After being stirred for $40 \mathrm{~min}$ at room temperature, the solvent was evaporated in vacuo and the residue was purified by silica gel column chromatography (PE-acetone $=5: 1$ ) to afford compound 14 (916 mg, 61\%). ${ }^{1} \mathrm{H}-\mathrm{NMR}\left(400 \mathrm{MHz}, \mathrm{CDCl}_{3}\right) \delta 1.04$ (s, 9H, $\left.\left(\mathrm{CH}_{3}\right)_{3} \mathrm{C}-\right)$, 2.03 (s, 3H, OAc), 3.68-3.70 (m, 2H, $\mathrm{H}_{4}{ }^{\prime}$ ), 3.79-3.82 (m, 2H, $\left.\mathrm{H}_{5}{ }^{\prime}\right), 3.85-3.87\left(\mathrm{~m}, 2 \mathrm{H}, \mathrm{H}_{4}{ }^{\prime \prime}\right), 4.18-4.20\left(\mathrm{~m}, 2 \mathrm{H}, \mathrm{H}_{5}{ }^{\prime \prime}\right), 5.54\left(\mathrm{~s}, 2 \mathrm{H}, \mathrm{H}_{1}{ }^{\prime \prime}\right), 5.61(\mathrm{~s}, 2 \mathrm{H}$, $\left.\mathrm{H}_{1}{ }^{\prime}\right), 7.35-7.66(\mathrm{~m}, 10 \mathrm{H}, \mathrm{ArH}), 8.09\left(\mathrm{~s}, 1 \mathrm{H}, \mathrm{H}_{2}\right) .{ }^{13} \mathrm{C}-\mathrm{NMR}\left(100 \mathrm{MHz}, \mathrm{CDCl}_{3}\right) \delta 170.7,155.3,149.2$, $147.8,135.5,133.2$, 129.7, 127.6, 126.2, 124.3, 75.0, 73.5, 71.0, 68.1, 62.9, 26.7, 20.7, 19.0. HRMS

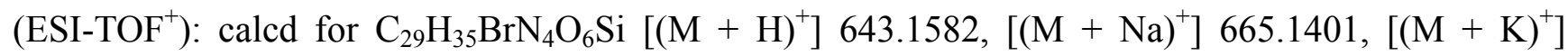
681.1135; found, 643.1563, 665.1377, 681.1117.

$N^{1}$-[(5"-Acetoxyethoxy)methyl]-N $N^{9}-\left[\left(5^{\prime}\right.\right.$-tert-butyldiphenylsilyloxyethoxy)methyl]-8-trifluoromethylhypoxanthine (15). To a solution of compound $14(576 \mathrm{mg}, 0.895 \mathrm{mmol})$ and $\mathrm{CuI}(206 \mathrm{mg}, 1.074$ mmol) in anhydrous DMF $(33 \mathrm{~mL})$, hexamethylphosphoric triamide $(2.39 \mathrm{~mL}, 13.425 \mathrm{mmol})$ and $\mathrm{FSO}_{2} \mathrm{CF}_{2} \mathrm{CO}_{2} \mathrm{Me}(1.71 \mathrm{~mL}, 13.425 \mathrm{mmol})$ were added successively. The reaction mixture was stirred for $20 \mathrm{~h}$ at $70{ }^{\circ} \mathrm{C}$ under argon, then cooled to room temperature, $22 \mathrm{~mL}$ of saturated aq. $\mathrm{NH}_{4} \mathrm{Cl}$ was added and the mixture was extracted with $200 \mathrm{~mL}$ of EA-hexanes (7:3). The organic layer was washed successively with sat. aq. $\mathrm{NaHCO}_{3}$, water and brine, dried $\left(\mathrm{Na}_{2} \mathrm{SO}_{4}\right)$, filtered, and concentrated under reduced pressure. The residue was purified by silica gel column chromatography (PE-acetone $=9: 2$ ) to afford compound 15 (238 mg, 42\%) and compound 16 (48 mg, 14\%), with compound 14 recovered (96 mg, 17\%). ${ }^{1} \mathrm{H}-\mathrm{NMR}\left(400 \mathrm{MHz}, \mathrm{CDCl}_{3}\right) \delta 1.03\left(\mathrm{~s}, 9 \mathrm{H},\left(\mathrm{CH}_{3}\right)_{3} \mathrm{C}-\right)$ ) 2.04 (s, 3H, OAc), 3.68-3.70 (m, $\left.2 \mathrm{H}, \mathrm{H}_{4}{ }^{\prime}\right), 3.79-3.81\left(\mathrm{~m}, 2 \mathrm{H}, \mathrm{H}_{5}{ }^{\prime}\right), 3.87-3.89\left(\mathrm{~m}, 2 \mathrm{H}, \mathrm{H}_{4}{ }^{\prime \prime}\right), 4.20-4.22\left(\mathrm{~m}, 2 \mathrm{H}, \mathrm{H}_{5}{ }^{\prime \prime}\right), 5.56\left(\mathrm{~s}, 2 \mathrm{H}, \mathrm{H}_{1}{ }^{\prime \prime}\right)$, $5.76\left(\mathrm{~s}, 2 \mathrm{H}, \mathrm{H}_{1}{ }^{\prime}\right), 7.35-7.66(\mathrm{~m}, 10 \mathrm{H}, \mathrm{ArH}), 8.18\left(\mathrm{~s}, 1 \mathrm{H}, \mathrm{H}_{2}\right) .{ }^{13} \mathrm{C}-\mathrm{NMR}\left(100 \mathrm{MHz}, \mathrm{CDCl}_{3}\right) \delta 170.7$, 
$156.3,149.4,149.3,138.6\left(\mathrm{~d},{ }^{2} J_{\mathrm{CF}}=41 \mathrm{~Hz}\right), 135.5,133.2,129.7,127.7,122.7,118.2\left(\mathrm{q},{ }^{1} J_{\mathrm{CF}}=270 \mathrm{~Hz}\right)$, 75.1, 73.5, 71.4, 68.3, 63.1, 63.0, 26.7, 20.8, 19.1. ${ }^{19} \mathrm{~F}-\mathrm{NMR}\left(470 \mathrm{MHz}, \mathrm{CDCl}_{3}\right) \delta$-63.4 (s). HRMS $\left(\right.$ ESI-TOF $\left.^{+}\right)$: calcd for $\mathrm{C}_{30} \mathrm{H}_{35} \mathrm{~F}_{3} \mathrm{~N}_{4} \mathrm{O}_{6} \mathrm{Si}\left[(\mathrm{M}+\mathrm{Na})^{+}\right]$655.2170, $\left[(\mathrm{M}+\mathrm{K})^{+}\right]$671.1904; found, 655.2169, 671.1913.

$N^{l}$-[(5"-Acetoxyethoxy)methyl]-N9-[(5'-hydroxylethoxy)methyl]-8-trifluoromethylhypoxanthine (16). A solution of 15 (182 mg, $0.288 \mathrm{mmol})$ in anhydrous THF $(35 \mathrm{~mL})$ was added $70 \% \mathrm{HF} \cdot \mathrm{Py} 1.3 \mathrm{~mL}$ at $-20{ }^{\circ} \mathrm{C}$. The mixture was stirred at $0{ }^{\circ} \mathrm{C}$ for $1 \mathrm{~h}$ and at room temperature over night. The reaction mixture was quenched with saturated aq. $\mathrm{NaHCO}_{3}$ at $0{ }^{\circ} \mathrm{C}$ and diluted with ethyl acetate, then partitioned and the water layer was washed with ethyl acetate again. The organic layer was combined, washed with brine, dried $\left(\mathrm{Na}_{2} \mathrm{SO}_{4}\right)$, filtered and concentrated under reduced pressure. The residue was purified by silica gel column chromatography $(\mathrm{PE}-\mathrm{EA}=1: 5)$ to afford the compound $16(91 \mathrm{mg}, 82 \%) .{ }^{1} \mathrm{H}-\mathrm{NMR}(400$ $\left.\mathrm{MHz} \mathrm{CDCl}_{3}\right) \delta 2.05$ (s, 3H, OAc), 3.68-3.74 (m, 4H, $\left.\mathrm{H}_{4}{ }^{\prime}, \mathrm{H}_{5}{ }^{\prime}\right), 3.87-3.89$ (m, 2H, $\left.\mathrm{H}_{4}{ }^{\prime \prime}\right), 4.19-4.22$ (m, $\left.2 \mathrm{H}, \mathrm{H}_{5}{ }^{\prime \prime}\right), 5.56\left(\mathrm{~s}, 2 \mathrm{H}, \mathrm{H}_{1}{ }^{\prime \prime}\right), 5.76\left(\mathrm{~s}, 2 \mathrm{H}, \mathrm{H}_{1}{ }^{\prime}\right), 8.23\left(\mathrm{~s}, 1 \mathrm{H}, \mathrm{H}_{2}\right) .{ }^{13} \mathrm{C}-\mathrm{NMR}\left(100 \mathrm{MHz}, \mathrm{CDCl}_{3}\right) \delta 170.8$, 156.2, 149.6, 149.3, $138.4\left(\mathrm{q},{ }^{2} J_{\mathrm{CF}}=41 \mathrm{~Hz}\right), 122.7,118.2\left(\mathrm{q},{ }^{1} J_{\mathrm{CF}}=270 \mathrm{~Hz}\right), 75.1,73.2,71.2,68.3$, 62.9, 61.4, 20.8; ${ }^{19} \mathrm{~F}-\mathrm{NMR}\left(470 \mathrm{MHz}, \mathrm{CDCl}_{3}\right) \delta$-63.4 (s). HRMS (ESI-TOF ${ }^{+}$): calcd for $\mathrm{C}_{14} \mathrm{H}_{17} \mathrm{~F}_{3} \mathrm{~N}_{4} \mathrm{O}_{6}$ $\left[(\mathrm{M}+\mathrm{Na})^{+}\right]$417.0992, [(M+K $\left.)^{+}\right], 433.0726$; found, 417.0991, 433.0730.

$N^{l}$-[(5"-Acetoxyethoxy)methyl]-N" $-\left[\left[5^{\prime}\right.\right.$-bis(phenylthio)phosphoryloxyethoxy]-methyl]-8-trifluoro-meth ylhypoxanthine (17). To a solution of $16(66 \mathrm{mg}, 0.167 \mathrm{mmol})$ in anhydrous pyridine $(5 \mathrm{~mL})$ was added TPSCl (302 mg, $1.00 \mathrm{mmol}$ ), PSS (571 $\mathrm{mg}, 1.50 \mathrm{mmol}$ ) [20], and tetrazole (105 $\mathrm{mg}$, $1.50 \mathrm{mmol}$ ), and the mixture was stirred at room temperature for $12 \mathrm{~h}$. The mixture was evaporated, and the residue was purified by silica gel column chromatography $(\mathrm{PE}-\mathrm{EA}=1: 2)$ to give compound 17 (86 mg, 79\%). ${ }^{1} \mathrm{H}$ NMR (400 MHz, $\mathrm{CDCl}_{3}$ ) $\delta 2.05$ (s, 3H, OAc), 3.82-3.84 (m, 2H, H4 ${ }^{\prime}$ ), 3.86-3.88 (m, $\left.2 \mathrm{H}, \mathrm{H}_{5}{ }^{\prime}\right), 4.18-4.21\left(\mathrm{~m}, 2 \mathrm{H}, \mathrm{H}_{4}{ }^{\prime \prime}\right), 4.31-4.35\left(\mathrm{~m}, 2 \mathrm{H}, \mathrm{H}_{5}{ }^{\prime \prime}\right), 5.56\left(\mathrm{~s}, 2 \mathrm{H}_{1} \mathrm{H}_{1}{ }^{\prime \prime}\right), 5.68\left(\mathrm{~s}, 2 \mathrm{H}, \mathrm{H}_{1}{ }^{\prime}\right)$, 7.33-7.52 (m, 10H, ArH), $8.22\left(\mathrm{~s}, 1 \mathrm{H}, \mathrm{H}_{2}\right) .{ }^{13} \mathrm{C}-\mathrm{NMR}\left(100 \mathrm{MHz}, \mathrm{CDCl}_{3}\right) \delta 170.8,156.3,149.7,149.3$, $138.5\left(\mathrm{q},{ }^{2} J_{\mathrm{CF}}=41 \mathrm{~Hz}\right), 135.3,129.7,129.4,125.9,122.7,118.2\left(\mathrm{q},{ }^{1} J_{\mathrm{CF}}=269 \mathrm{~Hz}\right), 75.2,73.0,69.0$, 68.4, 66.2, 62.9, 20.8. ${ }^{19} \mathrm{~F}$ NMR (470 MHz, $\left.\mathrm{CDCl}_{3}\right) \delta$-63.4 (s). ${ }^{31} \mathrm{P}-\mathrm{NMR}\left(\mathrm{D}_{2} \mathrm{O}, 243 \mathrm{MHz}\right.$, decoupled with $\left.{ }^{1} \mathrm{H}\right) \delta 50.41(\mathrm{~s})$. HRMS $\left(\right.$ ESI-TOF ${ }^{+}$): calcd for $\mathrm{C}_{30} \mathrm{H}_{35} \mathrm{~F}_{3} \mathrm{~N}_{4} \mathrm{O}_{6} \mathrm{Si}\left[(\mathrm{M}+\mathrm{H})^{+}\right], 659.1005$; found, 659.1006 .

$N^{1}-\left[\left(5^{\prime \prime}-\right.\right.$ Phosphonoxyethoxy)methyl]- $N^{9}-\left[\left[5^{\prime}\right.\right.$-(phenylthio) phosphoryloxyethoxy $]$ methyl]-8-trifluoromethylhypoxanthine (19). Compound $17(54 \mathrm{mg}, 0.082 \mathrm{mmol})$ was dissolved in $\mathrm{MeOH}(4 \mathrm{~mL})$, and a solution of acetyl chloride $(7 \mu \mathrm{L}, 0.098 \mathrm{mmol})$ in anhydrous $\mathrm{CH}_{2} \mathrm{Cl}_{2}(1 \mathrm{~mL})$ was added at $-20{ }^{\circ} \mathrm{C}$. The mixture was stirred at $0{ }^{\circ} \mathrm{C}$ for $30 \mathrm{~min}$ and raised to room temperature for $24 \mathrm{~h}$, then neutralized by sat. aq. $\mathrm{NaHCO}_{3}$ solution. The mixture was evaporated, and the residue was partitioned between $\mathrm{CH}_{2} \mathrm{Cl}_{2}$ and $\mathrm{H}_{2} \mathrm{O}$. The aqueous phase was extracted again with $\mathrm{CH}_{2} \mathrm{Cl}_{2}$, the organic layers were combined and washed with brine, dried $\left(\mathrm{Na}_{2} \mathrm{SO}_{4}\right)$, filtered and concentrated in vacuo. The residue was purified by silica gel column chromatography (PE-EA $=1: 10)$ to give compound 18 (31 mg). The deacetylated product 18 (31 mg, $0.050 \mathrm{mmol})$ was dissolved in anhydrous $\mathrm{CH}_{3} \mathrm{CN}(8 \mathrm{~mL})$. DIPEA (65 $\left.\mu \mathrm{L}, 0.375 \mathrm{mmol}\right)$ and $\mathrm{POCl}_{3}(28 \mu \mathrm{L}, 0.300 \mathrm{mmol})$ were added successively to the solution at $-20{ }^{\circ} \mathrm{C}$, and the mixture was stirred at $0{ }^{\circ} \mathrm{C}$ for $14 \mathrm{~h}$, and then added $5 \mathrm{~mL}$ of TEAB $(1 \mathrm{M}, \mathrm{pH} 7.5)$ at $0{ }^{\circ} \mathrm{C}$ and stirred at room 
temperature for $6 \mathrm{~h}$. After evaporation under reduced pressure, the residue was partitioned between $\mathrm{H}_{2} \mathrm{O}$ and $\mathrm{CHCl}_{3}$, and the aqueous layer was washed with $\mathrm{CHCl}_{3}$ and evaporated in vacuo. The residue was dissolved in $5 \mathrm{~mL}$ of TEAB buffer $(0.05 \mathrm{M}, \mathrm{pH} 7.5)$, then applied to a $\mathrm{C}_{18}$ reversed-phase column $(2.2 \times 25 \mathrm{~cm})$. The column was developed using a linear gradient of $0-40 \% \mathrm{CH}_{3} \mathrm{CN}$ in TEAB buffer (0.05 M, pH 7.5) within $30 \mathrm{~min}$ to afford 19 (27 mg, 41\% for two steps) as its triethylammonium salt. ${ }^{1} \mathrm{H}-\mathrm{NMR}\left(400 \mathrm{MHz}, \mathrm{D}_{2} \mathrm{O}\right) \delta$ 3.70-3.73 (m, 4H, $\left.\mathrm{H}_{4}{ }^{\prime}, \mathrm{H}_{5}{ }^{\prime}\right), 3.85-3.89\left(\mathrm{~m}, 2 \mathrm{H}, \mathrm{H}_{4}{ }^{\prime \prime}\right), 3.94-3.98$ (m, 2H, $\left.\mathrm{H}_{5}{ }^{\prime \prime}\right), 5.45\left(\mathrm{~s}, 2 \mathrm{H}, \mathrm{H}_{1}{ }^{\prime \prime}\right), 5.64\left(\mathrm{~s}, 2 \mathrm{H}, \mathrm{H}_{1}{ }^{\prime}\right), 7.09-7.29(\mathrm{~m}, 5 \mathrm{H}, \mathrm{ArH}), 8.41\left(\mathrm{~s}, 1 \mathrm{H}, \mathrm{H}_{2}\right) .{ }^{13} \mathrm{C}-\mathrm{NMR}$ $\left(100 \mathrm{MHz}, \mathrm{D}_{2} \mathrm{O}\right) \delta 157.6,150.9,149.5,138.8\left(\mathrm{q},{ }^{2} J_{\mathrm{CF}}=41 \mathrm{~Hz}\right), 132.7,129.6,128.9,127.7,122.1$, $117.8\left(\mathrm{q},{ }^{1} J_{\mathrm{CF}}=270 \mathrm{~Hz}\right), 76.4,73.3,69.3,64.9,64.3,46.6,8.2 .{ }^{19} \mathrm{~F}-\mathrm{NMR}\left(470 \mathrm{MHz}, \mathrm{D}_{2} \mathrm{O}\right) \delta-63.0(\mathrm{~s})$. ${ }^{31} \mathrm{P}-\mathrm{NMR}\left(\mathrm{D}_{2} \mathrm{O}, 243 \mathrm{MHz}\right.$, decoupled with $\left.{ }^{1} \mathrm{H}\right) \delta 1.10$ (s), 17.80 (s). HRMS (ESI-TOF ${ }^{-}$) calcd for $\mathrm{C}_{18} \mathrm{H}_{21} \mathrm{~N}_{4} \mathrm{O}_{10} \mathrm{P}_{2} \mathrm{SF}_{3}\left[(\mathrm{M}-\mathrm{H})^{-}\right], 603.0333$; found, 603.0331 .

$N^{1}$-[(5"-O-Phosphorylethoxy)methyl]- $N^{9}-\left[\left(5^{\prime}\right.\right.$-O-phosphorylethoxy)methyl]-8-trifluoromethylhypoxanthine-cyclic pyrophosphate (5). A solution of $19(5 \mathrm{mg}, 6.1 \mu \mathrm{mol})$ in anhydrous pyridine $(4.5 \mathrm{~mL})$ was added slowly over $20 \mathrm{~h}$, utilizing a syringe pump, to a mixture of $\mathrm{I}_{2}(36 \mathrm{mg}, 142 \mu \mathrm{mol})$ and $3 \AA$ molecular sieves $(0.36 \mathrm{~g})$, in pyridine $(40 \mathrm{~mL})$ at room temperature in the dark. The molecular sieves were filtered off with Celite and washed with $\mathrm{H}_{2} \mathrm{O}$. The combined filtrate was evaporated, and the residue was partitioned between $\mathrm{CHCl}_{3}$ and $\mathrm{H}_{2} \mathrm{O}$. The aqueous layer was evaporated, and the residue was dissolved in $0.05 \mathrm{M}$ TEAB buffer, which was applied to $\mathrm{C}_{18}$ reversed-phase column $(2.2 \times 25 \mathrm{~cm})$. The column was developed using a linear gradient of $0-20 \% \mathrm{CH}_{3} \mathrm{CN}$ in TEAB buffer $(0.05 \mathrm{M}, \mathrm{pH} 7.5)$ within $30 \mathrm{~min}$ to give 5 as its triethylammonium salt $(3.0 \mathrm{mg}, 71 \%) .{ }^{1} \mathrm{H}-\mathrm{NMR}\left(400 \mathrm{MHz}, \mathrm{D}_{2} \mathrm{O}\right) \delta$ 3.70-3.78 (m, $\left.4 \mathrm{H}, \mathrm{H}_{4}{ }^{\prime}, \mathrm{H}_{5}{ }^{\prime}\right), 3.81-3.83\left(\mathrm{~m}, 2 \mathrm{H}, \mathrm{H}_{4}{ }^{\prime \prime}\right), 3.88-3.90\left(\mathrm{~m}, 2 \mathrm{H}, \mathrm{H}_{5}{ }^{\prime \prime}\right), 5.54\left(\mathrm{~s}, 2 \mathrm{H}, \mathrm{H}_{1}{ }^{\prime \prime}\right), 5.75$ (s, $\left.2 \mathrm{H}, \mathrm{H}_{1}{ }^{\prime}\right), 8.49\left(\mathrm{~s}, 1 \mathrm{H}, \mathrm{H}_{2}\right) .{ }^{19} \mathrm{~F}-\mathrm{NMR}\left(470 \mathrm{MHz}, \mathrm{D}_{2} \mathrm{O}\right) \delta-62.5(\mathrm{~s}) .{ }^{31} \mathrm{P}-\mathrm{NMR}\left(\mathrm{D}_{2} \mathrm{O} 121.5 \mathrm{MHz}\right.$, decoupled with $\left.{ }^{1} \mathrm{H}\right) \delta-10.07\left(\mathrm{~d}, J_{\mathrm{P}, \mathrm{P}}=18.2 \mathrm{~Hz}\right),-10.42\left(\mathrm{~d}, J_{\mathrm{P}, \mathrm{P}}=18.2 \mathrm{~Hz}\right)$. HRMS (ESI-TOF $\left.{ }^{-}\right)$calcd for $\mathrm{C}_{12} \mathrm{H}_{15} \mathrm{~N}_{4} \mathrm{O}_{10} \mathrm{P}_{2} \mathrm{~F}_{3}\left[(\mathrm{M}-\mathrm{H})^{-}\right], 493.0143$; found, 493.0146.

$N^{1}-\left[\left(5^{\prime \prime}-\right.\right.$ Phosphonoxyethoxy)methyl]- $N^{9}-\left[\left(5^{\prime}\right.\right.$-Phosphonoxyethoxy)methyl]-8-trifluoromethylinosine (6). Compound 16 (20 mg, $0.051 \mathrm{mmol})$ was dissolved in methanol $(2 \mathrm{~mL})$. To the solution was added $\mathrm{K}_{2} \mathrm{CO}_{3}(1 \mathrm{mg}, 7.24 \mu \mathrm{mol})$ at room temperature and stirred for $6 \mathrm{~h}$. The mixture was neutralized by addition of $0.01 \mathrm{M} \mathrm{HCl}$ solution, and removed of the solvent in vacuo. The residue was partitioned between $\mathrm{CHCl}_{3}$ and $\mathrm{H}_{2} \mathrm{O}$, and the organic layer was washed with brine, dried $\left(\mathrm{Na}_{2} \mathrm{SO} 4\right)$, and evaporated, affording compound 20 (16 mg). Compound 20 (16 mg, $0.045 \mathrm{mmol}$ ) was dissolved in anhydrous $\mathrm{CH}_{3} \mathrm{CN}(5 \mathrm{~mL})$. DIPEA $(94 \mu \mathrm{L}, 0.54 \mathrm{mmol})$ and $\mathrm{POCl}_{3}(42 \mu \mathrm{L}, 0.45 \mathrm{mmol})$ were added successively to the solution at $-20{ }^{\circ} \mathrm{C}$. The mixture was stirred at $0{ }^{\circ} \mathrm{C}$ for $16 \mathrm{~h}$, and then added $5 \mathrm{~mL}$ of TEAB ( $1 \mathrm{M}, \mathrm{pH} 7.5)$ at $0{ }^{\circ} \mathrm{C}$ and stirred for $6 \mathrm{~h}$ at room temperature. After evaporation under reduced pressure, the residue was partitioned between $\mathrm{H}_{2} \mathrm{O}$ and $\mathrm{CHCl}_{3}$, and the aqueous layer was washed with $\mathrm{CHCl}_{3}$ and evaporated in vacuo. The residue was dissolved in $5 \mathrm{~mL}$ of TEAB buffer $(0.05 \mathrm{M}$, $\mathrm{pH} 7.5)$, and applied to a $\mathrm{C}_{18}$ reversed-phase column $(2.2 \times 25 \mathrm{~cm})$. The column was developed using a linear gradient of $0-40 \% \mathrm{CH}_{3} \mathrm{CN}$ in TEAB buffer $(0.05 \mathrm{M}, \mathrm{pH} 7.5)$ within $30 \mathrm{~min}$ to give 6 (22.3 $\mathrm{mg}$, $62 \%$ for two steps) as its triethylammonium salt. ${ }^{1} \mathrm{H}-\mathrm{NMR}\left(400 \mathrm{MHz}, \mathrm{D}_{2} \mathrm{O}\right) \delta 3.73-3.79\left(\mathrm{~m}, 4 \mathrm{H}, \mathrm{H}_{4}{ }^{\prime}, \mathrm{H}_{5}{ }^{\prime}\right)$, 3.85-3.92 (m, 4H, $\left.\mathrm{H}_{4}{ }^{\prime \prime}, \mathrm{H}_{5}{ }^{\prime \prime}\right), 5.45\left(\mathrm{~s}, 2 \mathrm{H}, \mathrm{H}_{1}{ }^{\prime \prime}\right), 5.77\left(\mathrm{~s}, 2 \mathrm{H}, \mathrm{H}_{1}{ }^{\prime}\right), 8.51\left(\mathrm{~s}, 1 \mathrm{H}, \mathrm{H}_{2}\right) .{ }^{13} \mathrm{C}-\mathrm{NMR}(100 \mathrm{MHz}$, $\left.\mathrm{D}_{2} \mathrm{O}\right) \delta 157.8,151.0,149.7,138.6\left(\mathrm{q},{ }^{2} J_{\mathrm{CF}}=41 \mathrm{~Hz}\right), 122.2,117.9\left(\mathrm{q},{ }^{1} J_{\mathrm{CF}}=270 \mathrm{~Hz}\right), 76.4,73.3,69.5$, 
69.2, 64.1, 63.8. ${ }^{19}$ F-NMR (470 MHz, $\left.\mathrm{D}_{2} \mathrm{O}\right) \delta$-62.9 (s). ${ }^{31} \mathrm{P}-\mathrm{NMR}\left(\mathrm{D}_{2} \mathrm{O}, 243 \mathrm{MHz}\right.$, decoupled with $\left.{ }^{1} \mathrm{H}\right) \delta$ 0.19 (s), 0.22 (s). HRMS (ESI-TOF) calcd for $\mathrm{C}_{12} \mathrm{H}_{17} \mathrm{~N}_{4} \mathrm{O}_{11} \mathrm{P}_{2} \mathrm{~F}_{3}\left[(\mathrm{M}-\mathrm{H})^{-}\right]$, 511.0248; found, 511.0246.

$N^{1}$-[(5'-Phosphonoxyethoxy)methyl]-5'-O-phosphoryl-2',3'-O-isopropylidene-inosine(23). Compound 21 (49 mg, $0.116 \mathrm{mmol}$ ) [6] was dissolved in $24 \mathrm{~mL}$ of methanol. To the solution was added $\mathrm{K}_{2} \mathrm{CO}_{3}(2 \mathrm{mg}$, $14.5 \mu \mathrm{mol}$ ) and stirred at room temperature for $6 \mathrm{~h}$. The mixture was neutralized by addition of $0.1 \mathrm{M}$ $\mathrm{HCl}$ solution, and removed of the solvent in vacuo. The residue was partitioned between $\mathrm{CHCl}_{3}$ and $\mathrm{H}_{2} \mathrm{O}$, and the organic layer was washed with brine, dried $\left(\mathrm{Na}_{2} \mathrm{SO}_{4}\right)$, and evaporated, affording compound 22 (38mg). Compound 22 (38 mg, 0.099 mmol) was dissolved in anhydrous $\mathrm{CH}_{3} \mathrm{CN}(5 \mathrm{~mL})$. DIPEA $(0.21 \mathrm{~mL}, 1.19 \mathrm{mmol})$ and $\mathrm{POCl}_{3}(91 \mu \mathrm{L}, 0.99 \mathrm{mmol})$ were added successively to the solution at $-20^{\circ} \mathrm{C}$. The mixture was stirred at $0{ }^{\circ} \mathrm{C}$ for $16 \mathrm{~h}$, and then was neutralized by addition of $1 \mathrm{M} \mathrm{NaOH}$ solution. And the resulting mixture was stirred at room temperature for $2 \mathrm{~h}$. After evaporated under reduced pressure, the residue was partitioned between $\mathrm{H}_{2} \mathrm{O}$ and $\mathrm{CHCl}_{3}$, and the aqueous layer was washed with $\mathrm{CHCl}_{3}$ and evaporated in vacuo. The residue was dissolved in $5 \mathrm{~mL}$ of TEAB buffer $(0.05 \mathrm{M}$, $\mathrm{pH} 7.5)$, and applied to a $\mathrm{C}_{18}$ reversed-phase column $(2.2 \times 25 \mathrm{~cm})$. The column was developed using a linear gradient of $0-40 \% \mathrm{CH}_{3} \mathrm{CN}$ in TEAB buffer $(0.05 \mathrm{M}, \mathrm{pH} 7.5)$ within $30 \mathrm{~min}$ to give $23(61 \mathrm{mg}$, $71 \%$ for two steps) as its triethylammonium salt. ${ }^{1} \mathrm{H}-\mathrm{NMR}\left(400 \mathrm{MHz}, \mathrm{D}_{2} \mathrm{O}\right) \delta 1.31,1.53$ (each s, each $3 \mathrm{H}$, $\left.2 \times \mathrm{CH}_{3}\right), 3.72-3.74\left(\mathrm{~m}, 2 \mathrm{H}, \mathrm{H}_{5}{ }^{\prime}\right), 3.85-3.89\left(\mathrm{~m}, 2 \mathrm{H}, \mathrm{CH}_{2} \mathrm{O}\right), 3.91-3.94\left(\mathrm{~m}, 2 \mathrm{H}, \mathrm{CH}_{2} \mathrm{OP}\right), 4.52-4.56(\mathrm{~m}, 1 \mathrm{H}$, $\left.\mathrm{H}_{4}{ }^{\prime}\right), 5.06\left(\mathrm{dd}, 1 \mathrm{H}, J_{\mathrm{H}^{\prime}, \mathrm{H} 4^{\prime}}=1.6 \mathrm{~Hz}, J_{\mathrm{H}^{\prime}, \mathrm{H}^{\prime}}=6.0 \mathrm{~Hz}, \mathrm{H}_{3}{ }^{\prime}\right), 5.29\left(\mathrm{dd}, 1 \mathrm{H}, J_{\mathrm{H}^{\prime}, \mathrm{H} 1^{\prime}}=2.8 \mathrm{~Hz}, J_{\mathrm{H}^{\prime}, \mathrm{H} 3^{\prime}}=6.0 \mathrm{~Hz}\right.$, $\left.\mathrm{H}_{2}{ }^{\prime}\right), 5.47\left(\mathrm{~d}, 1 \mathrm{H}, J_{\mathrm{H} 1^{\prime \prime} \mathrm{b}, \mathrm{H} 1^{\prime \prime} \mathrm{a}}=10.8 \mathrm{~Hz}, \mathrm{H}_{1^{\prime \prime} \mathrm{b}}\right), 5.51\left(\mathrm{~d}, 1 \mathrm{H}, J_{\mathrm{H} 1^{\prime \prime} \mathrm{a}, \mathrm{H} 1^{\prime \prime b}}=10.8 \mathrm{~Hz}, \mathrm{H}_{1^{\prime \prime} \mathrm{a}}\right), 6.17\left(\mathrm{~d}, 1 \mathrm{H}, J_{\mathrm{H}^{\prime}, \mathrm{H} 2^{\prime}}\right.$ $\left.=2.8 \mathrm{~Hz}, \mathrm{H}_{1}{ }^{\prime}\right), 8.23,8.34$ (each s, each $\left.1 \mathrm{H}, \mathrm{H}_{8}, \mathrm{H}_{2}\right) .{ }^{31} \mathrm{P}-\mathrm{NMR}\left(\mathrm{D}_{2} \mathrm{O}, 121.5 \mathrm{MHz}\right.$, decoupled with $\left.{ }^{1} \mathrm{H}\right) \delta$ 1.79 (s), 1.91 (s). HRMS(ESI-TOF ${ }^{-}$): calcd for $\mathrm{C}_{14} \mathrm{H}_{24} \mathrm{~N}_{4} \mathrm{O}_{13} \mathrm{P}_{2}\left[(\mathrm{M}-\mathrm{H})^{-}\right]$, 541.0742; found, 541.0733.

$N^{1}$-[(5"-Phosphonoxyethoxy)methyl]-5'-O-phosphorylinosine (7). A solution of 23 (25 mg, $\left.33.6 \mu \mathrm{mol}\right)$ in $60 \% \mathrm{HCOOH}(6 \mathrm{~mL})$ was stirred for $8 \mathrm{~h}$, and then $14 \mathrm{~mL}$ of TEAB $(1 \mathrm{M}, \mathrm{pH} 7.5)$ was added. The solution was evaporated under reduced pressure. The residue was dissolved in $0.05 \mathrm{M}$ TEAB buffer $(4.0 \mathrm{~mL})$, which was applied to $\mathrm{C}_{18}$ reversed-phase column $(2.2 \times 25 \mathrm{~cm})$. The column was developed using a linear gradient of $0-40 \% \mathrm{CH}_{3} \mathrm{CN}$ in TEAB buffer $(0.05 \mathrm{M}, \mathrm{pH} 7.5)$ within 30 min to afford 7 as its triethylammonium salt (20.2 mg. 85\%). ${ }^{1} \mathrm{H}-\mathrm{NMR}\left(400 \mathrm{MHz}, \mathrm{D}_{2} \mathrm{O}\right) \delta 3.72-3.74\left(\mathrm{~m}, 2 \mathrm{H}, \mathrm{H}_{5^{\prime}}\right)$, 3.85-3.88 (m, 2H, $\left.\mathrm{CH}_{2} \mathrm{O}\right), 3.98-4.01\left(\mathrm{~m}, 2 \mathrm{H}, \mathrm{CH}_{2} \mathrm{OP}\right), 4.23-4.26\left(\mathrm{~m}, 1 \mathrm{H}, \mathrm{H}_{4^{\prime}}\right), 4.34-4.37\left(\mathrm{~m}, 1 \mathrm{H}, \mathrm{H}_{3^{\prime}}\right)$, 4.59-4.61 (m, $\left.1 \mathrm{H}, \mathrm{H}_{2^{\prime}}\right), 5.46-5.52\left(\mathrm{~m}, 2 \mathrm{H}, \mathrm{H}_{1^{\prime \prime}}\right), 6.01\left(\mathrm{~d}, 1 \mathrm{H}, J_{\mathrm{H}^{\prime}, \mathrm{H} 2^{\prime}}=5.6 \mathrm{~Hz}, \mathrm{H}_{1^{\prime}}\right), 8.31,8.36$ (each s, each $\left.1 \mathrm{H}, \mathrm{H}_{8}, \mathrm{H}_{2}\right) .{ }^{31} \mathrm{P}-\mathrm{NMR}\left(\mathrm{D}_{2} \mathrm{O}, 243 \mathrm{MHz}\right.$, decoupled with $\left.{ }^{1} \mathrm{H}\right) \delta 0.81$ (s), 0.92 (s). HRMS (ESI-TOF ${ }^{-}$): calcd for $\mathrm{C}_{14} \mathrm{H}_{24} \mathrm{~N}_{4} \mathrm{O}_{13} \mathrm{P}_{2}\left[(\mathrm{M}-\mathrm{H})^{-}\right]$, 501.0429; found, 501.0426 .

\section{$N^{I}$-[(5'-Phosphonoxyethoxy)methyl]-5'-O-phosphoryl-2',3'-O-isopropylidene-8-trifluoromethylinosine}

(26). By a similar procedure that described for 6, 26 was synthesized from 24 [9], as its triethylammonium salt, in $57 \%$ yield for two steps. ${ }^{1} \mathrm{H}-\mathrm{NMR}\left(400 \mathrm{MHz}, \mathrm{D}_{2} \mathrm{O}\right) \delta 1.29,1.50$ (each s, each $\left.3 \mathrm{H}, 2 \times \mathrm{CH}_{3}\right), 3.71-3.73\left(\mathrm{~m}, 2 \mathrm{H}, \mathrm{H}_{5^{\prime}}\right), 3.82-3.96\left(\mathrm{~m}, 4 \mathrm{H}, \mathrm{CH}_{2} \mathrm{O}, \mathrm{CH}_{2} \mathrm{OP}\right), 4.35-4.39\left(\mathrm{~m}, 1 \mathrm{H}, \mathrm{H}_{4^{\prime}}\right), 5.19(\mathrm{dd}$, $\left.1 \mathrm{H}, J_{\mathrm{H} 3^{\prime}, \mathrm{H} 4^{\prime}}=4.0 \mathrm{~Hz}, J_{\mathrm{H}^{\prime}, \mathrm{H} 2^{\prime}}=6.8 \mathrm{~Hz}, \mathrm{H}_{3^{\prime}}\right), 5.40\left(\mathrm{~d}, 1 \mathrm{H}, J_{\mathrm{H} 1^{\prime \prime} \mathrm{a}, \mathrm{H} 1^{\prime \prime} \mathrm{b}}=10.8 \mathrm{~Hz}, \mathrm{H}_{1^{\prime \prime} \mathrm{a}}\right), 5.55-5.60(\mathrm{~m}, 2 \mathrm{H}$, $\left.\mathrm{H}_{1^{\prime \prime}}, \mathrm{H}_{2^{\prime}}\right), 6.23\left(\mathrm{~d}, 1 \mathrm{H}, J_{\mathrm{H}^{\prime}, \mathrm{H} 2^{\prime}}=2.0 \mathrm{~Hz}, \mathrm{H}_{1^{\prime}}\right), 8.44\left(\mathrm{~s}, 1 \mathrm{H}, \mathrm{H}_{2}\right) .{ }^{13} \mathrm{C}-\mathrm{NMR}\left(100 \mathrm{MHz}, \mathrm{D}_{2} \mathrm{O}\right) \delta 157.8$, $150.6,148.9,138.3\left(\mathrm{q},{ }^{2} J_{\mathrm{CF}}=40 \mathrm{~Hz}\right), 122.9,117.8\left(\mathrm{q},{ }^{1} J_{\mathrm{CF}}=270 \mathrm{~Hz}\right), 115.4,90.0,86.7,86.6,83.7,81.1$, 76.4, 69.2, 64.2, 63.8, 25.9, 24.2. ${ }^{19} \mathrm{~F}-\mathrm{NMR}\left(470 \mathrm{MHz}, \mathrm{D}_{2} \mathrm{O}\right) \delta-61.9$ (s). ${ }^{31} \mathrm{P}-\mathrm{NMR}\left(\mathrm{D}_{2} \mathrm{O}, 243 \mathrm{MHz}\right.$, 
decoupled with $\left.{ }^{1} \mathrm{H}\right) \delta 0.54$ (s), 0.70 (s). HRMS(ESI-TOF ${ }^{-}$): calcd for $\mathrm{C}_{17} \mathrm{H}_{23} \mathrm{~F}_{3} \mathrm{~N}_{4} \mathrm{O}_{13} \mathrm{P}_{2}\left[(\mathrm{M}-\mathrm{H})^{-}\right]$, 609.0612; found, 609.0615.

$N^{l}$-[(5"-Phosphonoxyethoxy)methyl]-5'-O-phosphoryl-8-trifluoromethylinosine (8). A solution of 26 $(15 \mathrm{mg}, 18.47 \mu \mathrm{mol})$ in $10 \% \mathrm{HCOOH}(7.5 \mathrm{~mL})$ was stirred at room for $60 \mathrm{~h}$, and then $11 \mathrm{~mL}$ of TEAB ( $1 \mathrm{M}, \mathrm{pH} 7.5$ ) was added. The solution was evaporated in vacuo. The residue was dissolved in $0.05 \mathrm{M}$ TEAB buffer $(2.0 \mathrm{~mL})$, which was applied to $\mathrm{C}_{18}$ reversed-phase column $(2.2 \mathrm{~cm} \times 25 \mathrm{~cm})$. The column was developed using a linear gradient of $0-40 \% \mathrm{CH}_{3} \mathrm{CN}$ in TEAB buffer $(0.05 \mathrm{M}, \mathrm{pH} 7.5)$ within $30 \mathrm{~min}$ to afford compound $8(9.7 \mathrm{mg}, 68 \%)$ as its triethylammonium salt, with the compound 26 (2.2 mg, 15\%) recovered. ${ }^{1} \mathrm{H}-\mathrm{NMR}\left(400 \mathrm{MHz}, \mathrm{D}_{2} \mathrm{O}\right) \delta 3.76-3.78\left(\mathrm{~m}, 2 \mathrm{H}, \mathrm{H}_{5^{\prime}}\right), 3.87-3.91\left(\mathrm{~m}, 2 \mathrm{H}, \mathrm{CH}_{2} \mathrm{O}\right)$, 4.02-4.13 (m, 2H, $\left.\mathrm{CH}_{2} \mathrm{OP}\right), 4.21-4.25\left(\mathrm{~m}, 1 \mathrm{H}, \mathrm{H}_{4^{\prime}}\right), 4.55-4.57\left(\mathrm{~m}, 1 \mathrm{H}, \mathrm{H}_{3^{\prime}}\right), 5.20-5.23\left(\mathrm{~m}, 1 \mathrm{H}, \mathrm{H}_{2^{\prime}}\right), 5.46$ $\left(\mathrm{d}, 1 \mathrm{H}, J_{\mathrm{H} 1^{\prime \prime} \mathrm{b}, \mathrm{H} 1^{\prime \prime \mathrm{a}}}=10.6 \mathrm{~Hz}, \mathrm{H}_{1}{ }^{\prime}\right), 5.59\left(\mathrm{~d}, 1 \mathrm{H}, J_{\mathrm{H} 1^{\prime \prime} \mathrm{a}, \mathrm{H} 1^{\prime \prime} \mathrm{b}}=10.6 \mathrm{~Hz}, \mathrm{H}_{1^{\prime \prime} \mathrm{a}}\right), 5.99\left(\mathrm{~d}, 1 \mathrm{H}, J_{\mathrm{H}^{\prime \prime}, \mathrm{H} 2^{\prime}}=5.6 \mathrm{~Hz}\right.$, $\left.\mathrm{H}_{1^{\prime}}\right), 8.47\left(\mathrm{~s}, 1 \mathrm{H}, \mathrm{H}_{2}\right) .{ }^{13} \mathrm{C}-\mathrm{NMR}\left(100 \mathrm{MHz}, \mathrm{D}_{2} \mathrm{O}\right) \delta 157.9,150.3,149.4,138.9\left(\mathrm{q},{ }^{2} J_{\mathrm{CF}}=40 \mathrm{~Hz}\right), 123.2$, $117.8\left(\mathrm{q},{ }^{1} J_{\mathrm{CF}}=269 \mathrm{~Hz}\right), 89.8,84.4,76.3,72.0,70.0,69.3,64.4,64.1 .{ }^{19} \mathrm{~F}-\mathrm{NMR}\left(470 \mathrm{MHz}, \mathrm{D}_{2} \mathrm{O}\right) \delta$ -61.7 (s). ${ }^{31} \mathrm{P}-\mathrm{NMR}\left(\mathrm{D}_{2} \mathrm{O}, 121.5 \mathrm{MHz}\right.$, decoupled with $\left.{ }^{1} \mathrm{H}\right) \delta$ 6.25(s), 6.27 (s). HRMS(ESI-TOF ${ }^{-}$): calcd for $\mathrm{C}_{14} \mathrm{H}_{19} \mathrm{~F}_{3} \mathrm{~N}_{4} \mathrm{O}_{13} \mathrm{P}_{2}\left[(\mathrm{M}-\mathrm{H})^{-}\right], 569.0303$; found, 569.0315 .

\section{Conclusion}

In conclusion, we have successfully synthesized 8-CF 3 -cIDPDE (5) via construction of $N^{l}$, $N^{9}$-disubstituted hypoxanthine, trifluoromethylation and intramolecular condensation. A series of novel acyclic analogues of cADPR, compounds 6-8, were also synthesized by concise synthetic routes. With the special properties of trifluoromethyl, $8-\mathrm{CF}_{3}-\mathrm{cIDPDE}$ and the acyclic derivatives are expected to provide useful agents to explore the cADPR/RyR $\mathrm{Ca}^{2+}$ signalling system and illuminate the structure-activity relationship of cADPR analogues.

\section{Acknowlegements}

This study was supported by the National Natural Sciences Foundation of China (Grant no. 90713005, 20832008) and the Ministry of Education of China (Grant no. 200800010078).

\section{References}

1. Clapper, D.L.; Walseth, T.F.; Dargie P.J.; Lee, H C. Pyridine nucleotide metabolites stimulate calcium release from sea urchin egg microsomes desensitized to inositol trisphosphate. J. Biol Chem. 1987, 262, 9561-9568.

2. Guse, A.H. Biochemistry, biology, and pharmacology of cyclic adenosine diphosphoribose (cADPR). Curr. Med. Chem. 2004, 11, 847-855.

3. Shuto S.; Matsuda A. Chemistry of cyclic ADP-ribose and its analogs. Curr. Med. Chem. 2004, 11, 827-845.

4. Zhang, L.H.; Guse, A.H. Cyclic ADP-ribose analogues with minimal structure: synthesis and calcium-release activity. In Drug Discovery Research: New Frontiers in the Post-Genomic Era; Huang, Z.W., Ed.; John Wiley \& Sons, Inc.: New York, NY, USA, 2007; pp.186-202. 
5. Oliviero, G.; D’Errico, S.; Borbone, N.; Amato, J.; Piccialli, V.; Varra, M.; Piccialli, G.; Mayol, L. A solid-phase approach to the synthesis of $N$-1-alkyl analogues of cyclic inosine-diphosphate-ribose (cIDPR). Tetrahedron 2010, 66, 1931-1936.

6. Gu, X.F.; Yang, Z.J.; Zhang, L R.; Zhang, L.H. Synthesis and biological evaluation of novel membrane-permeant cyclic ADP-ribose mimics: $N^{1}-\left[\left(5^{\prime \prime}-O\right.\right.$-phosphorylethoxy)-methyl $]-5^{\prime}-O$ phosphorylinosine 5',5"-cyclic pyrophosphate (cIDPRE) and 8-substituted derivatives. J. Med. Chem. 2004, 47, 5674-5682.

7. Guse, A.H.; Gu, X.F.; Zhang, L.R.; Weber, K.; Zhang, L.H. A minimal structural analogue of cyclic ADP-ribose. J. Biol. Chem. 2005, 280, 15952-15959.

8. McClinton, M.A.; McClinton, D.A. Trifluoromethylations and related reactions in organic chemistry. Tetrahedron 1992, 48, 6555-6666

9. Dong, M.; Kirchberger, T.; Huang, X.C.; Yang, Z.J.; Zhang, L.R.; Guse, A.H.; Zhang, L.H. Trifluoromethylated Cyclic-ADP- Ribose Mimic: Synthesis of 8-trifluoromethyl- $N^{1}$ [(5"-O-Phosphorylethoxy)methyl]-5'-O-phosphorylinosine-5',5"'-cyclic pyrophosphate (8-CF $3^{-}$ cIDPRE) and its calcium release activity in T Cells. Org. Biomol. Chem. 2010, 8, 4705-4715.

10. Walseth, T.F.; Lee, H.C. Synthesis and characterization of antagonists of cyclic-ADP-ribose-induced $\mathrm{Ca}^{2+}$ release. Biochim. Biophys. Acta, Mol. Cell Res. 1993, 1178, 235-242.

11. Gu, Q.M.; Sih, C.J. Cyclic-ADP-ribose: synthesis and structure. J. Am. Chem. Soc. 1994, 116, 7481-7486.

12. Canales, J.; Fernández, A.; Rodrigues, A.J.; Ferreira, R.; Ribeiro, J.M.; Cabezas, A.; Costas, M.J.; Cameselle, J.C. Hydrolysis of the phosphoanhydride linkage of cyclic ADP-ribose by the $\mathrm{Mn}^{2+}$-dependent ADP-ribose/CDP-alcohol pyrophosphatase. FEBS Letters 2009, 583: 1593-1598.

13. Wu, H.M.; Yang, Z.J.; Zhang, L.R.; Zhang, L.H. Concise Synthesis of Acyclic Analogues of cADPR with Ether Chain as Northern Moiety. New J. Chem. 2010, 34, 956-966.

14. Li, X.; Vince, R. Synthesis and biological evaluation of purine derivatives incorporating metal chelating ligands as HIV integrase inhibitors. Bioorg. Med. Chem. 2006, 14, 5742-5755.

15. Robins, M.J.; Hatfield, P.W. Convenient and high-yield syntheses of $N$-[(2-hydroxyethoxy)methyl] heterocycles as "acyclic nucleoside" analogues. Can. J. Chem. 1982, 60, 547-553

16. Lazrek, H.B.; Taourirte, M.; Barascut, J.L.; Imbach, J.L. Solid-liquid phase catalysis I: study of the N-alkylation of purines and pyrimidines. Nucleos. Nucleot. 1991, 10, 1285-1293.

17. Chen, Q.Y.; Wu, S.W. Methyl fluorosulphonyldifluoroacetate, a new trifluoromethylating agent. J. Chem. Soc., Chem. Commun. 1989, 705-706.

18. Lalonde, M.; Chan, T.H. Use of organosilicon reagents as protective groups in organic synthesis. Synthesis 1985, 817-845.

19. Nicolaou, K.C.; Webber, S.E. Stereocontrolled total synthesis of lipoxins B. Synthesis 1986, 453-461.

20. Yamaguchi, K.; Honda, S.; Hata, T. A convenient method for the preparation of S,S-diaryl phosphorodithioates. Chem. Lett. 1979, 507-508.

21. Sekine, M.; Kamimura, T.; Hata, T. A convenient method for the synthesis of $P^{I}$ (7-methylguanosine-5') $P^{2}$ - (ribonuceoside-5') diphosphates. J. Chem. Soc. Perkin Trans. I 1985, 997-1000. 
22. Yeom, C.E.; Lee, S.Y.; Kim, Y.J.; Kim, B.M. Mild and chemoselective deacetylation method using a catalytic amount of acetyl chloride in methanol. Syn. Lett. 2005, 10, 1527-1530.

23. Li, L.J.; Lin, B.C.; Yang, Z.J.; Zhang, L.R.; Zhang, L.H. A concise route for the preparation of nucleobase-simplified cADPR mimics by click chemistry. Tetrahedron Lett. 2008, 49, 4491-4493.

24. Fukuoka, M.; Shuto, S.; Shirato, M.; Sumita, Y.; Veno, Y.; Matsuda, A. An efficient synthesis of cyclic IDP- and cyclic condensation method to form an intramolecular pyrophosphate linkage as a key step. An entry to a general method for the chemical synthesis of synthesis of cyclic ADP-ribose analogues. J. Org. Chem. 2000, 65, 5238-5248.

(C) 2010 by the authors; licensee MDPI, Basel, Switzerland. This article is an open access article distributed under the terms and conditions of the Creative Commons Attribution license (http://creativecommons.org/licenses/by/3.0/). 